\title{
Urinary Neutrophil Gelatinase-associated Lipocalin: As an Early Marker for Diabetic Nephropathy
}

\author{
Hoda Gouda Bakr'1 ${ }^{1}$ Khaled Ahmed Elbana ${ }^{2}$, Abeer Abd Alla Fekry ${ }^{2}$, Mahmoud Samir Elkot ${ }^{1}$
}

Departments of ${ }^{1}$ Internal Medicine and ${ }^{2}$ Clinical Pathology, Faculty of Medicine, Zagazig University, Egypt

*Corresponding Author: Mahmoud Samir Elkot, Mobile: (+20)01063667588, Email: Doctorelkot1988@ gmail.com

\begin{abstract}
Background: Diabetes mellitus is a group of metabolic diseases characterized by hyperglycemia resulting from defects in insulin secretion, insulin action, or both. Diagnostic marker to detect diabetic nephropathy at early stage is important as early intervention can slow the loss of kidney function and reduce adverse outcomes. Neutrophil gelatinaseassociated lipocalin (NGAL) is a small (25-kd) protein that belongs to the lipocalin protein family. Urinary NGAL (uNGAL) levels have been demonstrated to be a very promising marker especially in acute kidney disease.

Objective: To measure urinary neutrophil gelatinase-associated lipocalin (NGAL) as an early marker for diagnosis of diabetic nephropathy in type 2 diabetes mellitus (T2DM) patients.

Patients and Methods: The study was conducted on 84 subjects, from (18- 80 years old), 45 (53.5\%) were males and $39(46.4 \%)$ were females, with mean age $(58.18 \pm 13.98)$. They were collected from Endocrinology and Nephrology Clinic after a written consent was taken from the patients at Zagazig University Hospital.

Results: Urinary NGAL is higher in diabetic patients compared with non-diabetic controls with high significant difference ( $\mathrm{p}<0.0001)$. In our result we found a positive correlation between NGAL and the duration of DM $(r=0.279$, $\mathrm{p}=0.027)$. There was a positive correlation between NGAL level and HbA1C, with significant difference $(\mathrm{r}=0.778, \mathrm{p}$ $=0.000)$ in patients groups. Our results showed a positive correlation between NGAL and FPG $(r=0.562)(p<0.001)$ and $2 \mathrm{hPPPG}(\mathrm{r}=0.687)(\mathrm{p}<0.001)$. There was a positive correlation between NGAL level and albumin-creatinine ratio $(\mathrm{Alb} / \mathrm{Cr})$ with significant difference $(\mathrm{r}=0.888, \mathrm{p}<0.001)$ in patients groups.
\end{abstract}

Conclusion: There was a high significant difference in the level of urinary NGAL in diabetic patients than control subjects. Urine NGAL had a positive correlation with albumin-creatinine ratio, duration of DM, HbA1c.

Keywords: Associated lipocalin, Neutrophil gelatinase, T2DM, Diagnosis.

\section{INTRODUCTION}

Diabetes mellitus is a group of metabolic diseases characterized by hyperglycemia resulting from defects in insulin secretion, insulin action or both. The chronic hyperglycemia of diabetes is associated with long-term damage, dysfunction and failure of various organs especially the eyes, kidneys, nerves, heart and blood vessels ${ }^{(1)}$.

Several pathogenic processes are involved in the development of diabetes. These range from autoimmune destruction of the 13-cells of the pancreas with consequent insulin deficiency to abnormalities that result in resistance to insulin action. The basis of the abnormalities in carbohydrate, fat, and protein metabolism in diabetes is due to deficient action of insulin on target tissues, which results from inadequate insulin secretion and/or diminished tissue responses to insulin at one or more points in the complex pathways of hormone action ${ }^{(2)}$.

Diabetes has become the primary cause of endstage renal disease (ESRD). Early diagnosis of diabetes and early intervention are critical in preventing the normal progression to renal failure seen in many patients with type 1 and a significant percentage of $\mathrm{T}^{2} \mathrm{DM}^{(3)}$.

Diabetic nephropathy is associated with an increased risk of all-cause mortality, cardiovascular disease and progression to end stage renal disease
(ESRD), requiring costly renal replacement therapy in the form of dialysis or transplantation. Diagnostic marker to detect diabetic nephropathy at early stage is important as early intervention can slow the loss of kidney function and reduce adverse outcomes. The appearance of small amount of protein albumin in urine, called microalbuminuria has been accepted as the earliest marker for development of diabetic nephropathy. However, it has been reported that a large proportion of renal impairment occurs even before appearance of microalbuminuria ${ }^{(4)}$.

It is necessary to implement different strategies for detecting early diabetic nephropathy in patients with T2DM aiming to delay its progression and improve outcomes. Increased levels of urinary biomarkers can be detected in T2DM patients before the onset of significant albuminuria. There are several glomerular and tubular biomarkers predicting onset or progression of nephropathy in patient with diabetes and may be used as an early marker of renal injury in diabetic nephropathy, this would play a significant role in clinical diagnosis and treatment approaches in diabetic care $^{(5)}$.

Neutrophil gelatinase-associated lipocalin (NGAL) is a small $(25-\mathrm{kd})$ protein that belongs to the lipocalin protein family. NGAL is produced in epithelial cells and neutrophils in most tissues. It was found in activated neutrophils, in accordance with its 
role as an innate antibacterial factor ${ }^{(\boldsymbol{6})}$. Urinary NGAL (u-NGAL) levels have been demonstrated to be a very promising marker, especially in acute kidney disease. Also plasma NGAL (p-NGAL) has been shown to be a promising marker of tubular damage in both acute and chronic kidney damage ${ }^{(7)}$.

Neutrophil gelatinase associated lipocalin (NGAL), is produced and secreted into the urine in response to ischemic kidney damage and is therefore a promising early and sensitive biomarker of diabetic nephropathy. The appearance of neutrophil gelatinaseassociated lipocalin (NGAL) in the urine of patients may indicate early glomerular injury, and this has been demonstrated at earlier stage than the appearance of microalbuminuria ${ }^{(8)}$.

Evidence also suggests that NGAL somehow may be involved in the pathophysiological process of chronic renal diseases, such as polycystic kidney disease and glomerulonephritis. Neutrophil gelatinase associated lipocalin (NGAL) levels clearly correlate with severity of renal impairment, probably expressing the degree of active damage underlying the chronic condition. For all these reasons neutrophil gelatinase associated lipocalin (NGAL) may become one of the most promising next-generation biomarkers in clinical nephrology and beyond ${ }^{(6)}$.

The study aimed to measure urinary neutrophil gelatinase-associated lipocalin (NGAL) as an early marker for diagnosis of diabetic nephropathy in T2DM patients.

\section{PATIENTS AND METHODS}

The study was conducted on 84 subjects, from (1880 years old), $45(53.5 \%)$ were males and $39(46.4 \%)$ were females (table 1), with mean age $(58.18 \pm 13.98)$. They were collected from Endocrinology and Nephrology Clinic at Zagazig University Hospital. The subjects were divided into 2 groups: Controls group: 21 healthy control subjects of comparative age and sex. Their mean age was $57.52 \pm 13.45$ years. It included 13 males and 8 females, and Patients group: 63 patients had T2DM.

Exclusion Criteria: Type 1 DM, urinary tract infection, fever, glomerulonephritis and proteinuria due other causes than diabetes mellitus, drugs causing proteinuria for example (amlodipine, amoxicillin and azithromycin), pregnancy, patient with hepatic disease, malignancy, and hypertension.

\section{Ethical approval:}

An approval of the study was obtained from Zagazig University academic and ethical committee. Every patient signed an informed written consent for acceptance of the operation.
This work has been carried out in accordance with The Code of Ethics of the World Medical Association (Declaration of Helsinki) for studies involving humans.

All subjects of this study were subjected to the following:

A) Medical history taking.

B) Thorough clinical examination.

C) Anthropometric measurements including: Weight, height, body mass index.

D) Laboratory investigations:

1) Complete blood picture.

2) Liver enzymes test (ALT, AST) (IU/L) (serum albumin) (mg/dl) using enzymatic colorimetry methods.

3) Estimation of GFR using Cockcroft Gault equation $[\mathrm{ml} / \mathrm{min}]$; e $\mathrm{CoCr}=(140$-age (in years $))$ $\times$ weight (in kilograms) / $72 \times$ serum creatinine, multiply by 0.85 if female (in $\mathrm{mg} / \mathrm{dl}$ ) ${ }^{(9)}$. Fasting plasma glucose (after fasting 8 hours), two hours post prandial blood glucose were measured using an automated glucose oxidase method using Behring Diagnostics Reagents (SVR Glucose Test; Behring, La Jolla, CA).

4) $\mathrm{HbA} 1 \mathrm{c} \%$ by quantitative colorimetric determination of glycohemoglobin in blood.

5) Albumin creatinine ratio in urine by enzyme immunoassay $(\mathrm{mg} / \mathrm{g})$.

6) Measurement of urinary neutrophil gelatinase associated lipocalin in urine samples of T2DM patients with different grades of albuminuria by ELISA.

\section{Statistical Analysis}

Data were collected, revised, coded and entered to the Statistical Package for the Social Sciences (IBM SPSS) version 20 . The quantitative data were presented as mean, standard deviations and range when their distribution was found parametric while qualitative data were presented as number and percentages. The comparison between two independent groups with qualitative data was done by using Chi-square test and with quantitative data and parametric distribution was done by using independent t-test. Spearman correlation coefficients were used to assess the correlation between two quantitative parameters in the same group. P-value $<0.05$ was considered significant and $<0.01$ highly significant.

\section{RESULTS}

Table (1) showed no statistical significant difference as regard age, gender, weight, BMI on comparing the studied and control groups and statistical significant difference was found as regard systolic and diastolic blood pressure. 
Table (1): Comparison between all studied groups as regard different clinical parameters

\begin{tabular}{|c|c|c|c|c|}
\hline & Control group & Patients group & \\
\hline & & No. $=21$ & No. $=63$ & P-value \\
\hline \multirow{2}{*}{ Gender } & Female & $8(38.1 \%)$ & $31(49.2 \%)$ & \multirow{2}{*}{0.377} \\
\hline & Male & $13(61.9 \%)$ & $32(50.8 \%)$ & \\
\hline \multirow{2}{*}{ Age (years) } & Mean \pm SD & $57.52 \pm 13.45$ & $55.78 \pm 11.96$ & \multirow{2}{*}{0.576} \\
\hline & Range & $25-78$ & $33--81$ & \\
\hline Weight $(\mathrm{kg})$ & Mean \pm SD & $74.29 \pm 12.74$ & $75.88 \pm 12.09$ & 0.579 \\
\hline BMI $\left(\mathrm{kg} / \mathrm{m}^{2}\right)$ & Mean \pm SD & $24.69 \pm 3.21$ & $25.28 \pm 5.18$ & 0.628 \\
\hline $\mathrm{SBP}(\mathrm{mmHg})$ & Mean \pm SD & $120.19 \pm 6.89$ & $131.67 \pm 10.53$ & $<0.001 * *$ \\
\hline $\mathrm{DBP}(\mathrm{mmHg})$ & Mean \pm SD & $82.90 \pm 3.35$ & $89.43 \pm 8.58$ & $<0.001 * *$ \\
\hline Duration of DM (years) & Mean \pm SD & - & $9.09 \pm 4.07$ & - \\
\hline
\end{tabular}

**: Highly-significant, $\mathrm{BMI}=$ body mass index

Table (2) showed that on comparing between the studied groups, there was no statistical significant difference as regard $\mathrm{Hb}$, creatinine, AST, ALT, HDL-C and high statistical significant difference was found as regard FPG, 2hpppG, HbA1C, TG, TC LDL-C, and Alb/Cr and statistical significant difference as regard GFR.

Table (2): Comparison between all studied groups and control group as regard to laboratory parameters

\begin{tabular}{|l|l|c|c|c|}
\hline \multicolumn{2}{|l}{} & Control group & Patients group & \\
\cline { 3 - 5 } \multicolumn{2}{|l|}{} & No. $=\mathbf{2 1}$ & No. $=\mathbf{6 3}$ & P-value \\
\hline Hb $(\mathrm{g} / \mathrm{dl})$ & Mean \pm SD & $11.19 \pm 1.45$ & $10.71 \pm 1.04$ & 0.101 \\
\hline Creatinine $(\mathrm{mg} / \mathrm{dl})$ & Mean \pm SD & $1.06 \pm 0.23$ & $1.09 \pm 0.11$ & 0.425 \\
\hline AST $(\mathrm{Iu} / \mathrm{l})$ & Mean \pm SD & $22.76 \pm 5.89$ & $25.57 \pm 5.17$ & 0.162 \\
\hline ALT $(\mathrm{Iu} / \mathrm{l})$ & Mean \pm SD & $21.90 \pm 1.33$ & $26.10 \pm 5.56$ & 0.099 \\
\hline GFR $\left(\mathrm{ml} / \mathrm{min} / 1.73 \mathrm{~m}^{2}\right)$ & Mean \pm SD & $107.53 \pm 6.59$ & $90.32 \pm 8.51$ & $<0.001^{* *}$ \\
\hline FPG $(\mathrm{mg} / \mathrm{dl})$ & Mean \pm SD & $82.29 \pm 9.32$ & $178.40 \pm 20.81$ & $<0.001^{* *}$ \\
\hline 2hPPPG $(\mathrm{mg} / \mathrm{dl})$ & Mean \pm SD & $126.14 \pm 9.85$ & $250.02 \pm 44.19$ & $<0.001^{* *}$ \\
\hline HbA1C $(\%)$ & Mean \pm SD & $5.46 \pm 0.45$ & $8.73 \pm 1.39$ & $<0.001^{* *}$ \\
\hline TC $(\mathrm{mg} / \mathrm{dl})$ & Mean \pm SD & $184.24 \pm 23.15$ & $255.05 \pm 42.28$ & $<0.001^{* *}$ \\
\hline TG $(\mathrm{mg} / \mathrm{dl})$ & Mean \pm SD & $153.10 \pm 18.90$ & $178.54 \pm 25.29$ & $<0.001^{* *}$ \\
\hline HDL- C $(\mathrm{mg} / \mathrm{dl})$ & Mean \pm SD & $41.05 \pm 3.47$ & $34.97 \pm 3.12$ & 0.057 \\
\hline LDL- C $(\mathrm{mg} / \mathrm{dl})$ & Mean \pm SD & $91.81 \pm 3.73$ & $132.32 \pm 34.26$ & $0.001 * *$ \\
\hline Alb/ Cr $(\mathrm{mg} / \mathrm{g})$ & Mean \pm SD & $20.87 \pm 4.72$ & $266.52 \pm 35.13$ & $0.001^{* *}$ \\
\hline NGAL $(\mathrm{ng} / \mathrm{dl})$ & Mean \pm SD & $3.18 \pm 0.64$ & $185.03 \pm 15.23$ & $0.001 * *$ \\
\hline
\end{tabular}

**: Highly-significant

In comparison between control and patients groups as regard NGAL we found a high statistical significant difference $(\mathrm{P}<0.001)$ (Figure 1).

\section{NGAL (ng/dl )}

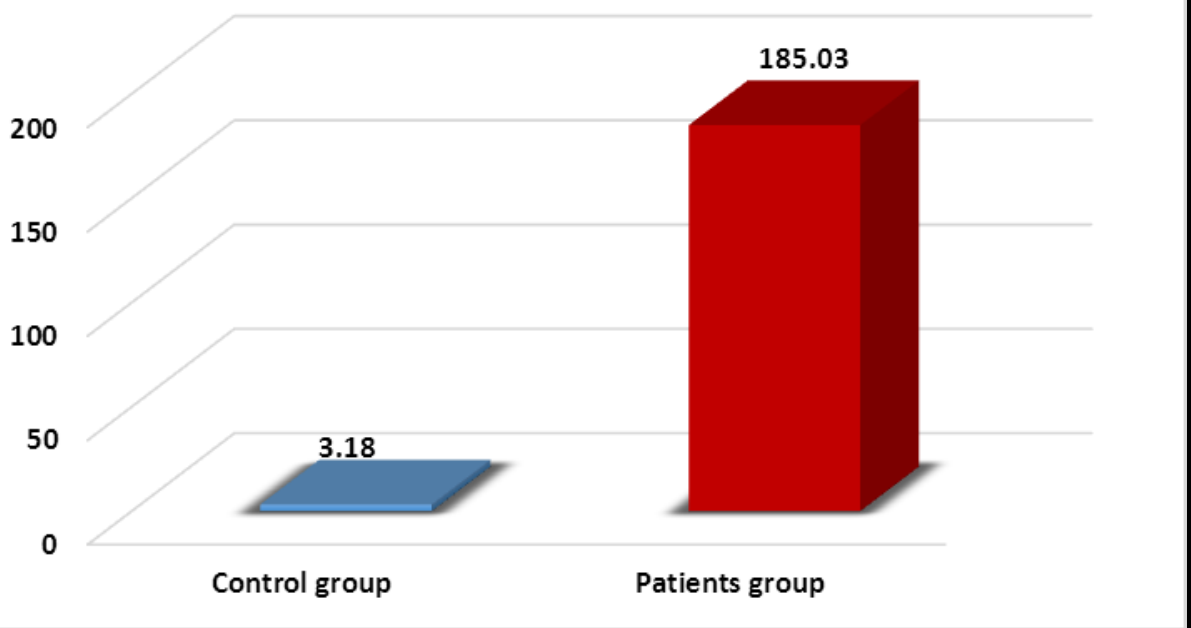

Fig. (1): Comparison between the patients groups as regard NGAL 


\section{DISCUSSION}

Our study showed that that urinary NGAL is higher in diabetic patients compared with non-diabetic controls with high significant difference. These results were in agreement with those reported by Elkhidir $\boldsymbol{e t}$ al. ${ }^{(10)}$ who studied 60 T2DM patients and 20 nondiabetic control subjects, and found that urinary NGAL is higher in T2DM patients compared with nondiabetic controls with high significant difference $(\mathrm{p}<$ 0.0001). Our results also were similar to the results of Nielsen et al. ${ }^{(11)}$ who studied 69 T2DM patients and 75 control subjects and they found that NGAL was higher $(279 \pm 58 \mathrm{ng} / \mathrm{ml}$ vs $263 \pm 38 \mathrm{ng} / \mathrm{ml})$ in T2DM patients than control patients respectively with high significant difference $(\mathrm{p}<0.001)$.

Plasma NGAL is filtered by the glomerulus and largely reabsorbed by the proximal tubules by an efficient megalin-dependent endocytosis mechanism. Thus, the excretion of NGAL in the urine happens only when the reabsorption by proximal renal tubule is blocked due to an injury that stimulates the synthesis of NGAL. ${ }^{(12)}$. It correlates with severity of renal impairment via expressing different concentrations according to the degree of chronic failure condition. It has been found that urine NGAL corresponds positively with major parameters used currently in evaluating DN and renal impairment such as cystatin $\mathrm{C}$, blood urea nitrogen and serum creatinine ${ }^{\mathbf{( 1 1 )}}$.

In our result we found a positive correlation between NGAL and the duration of DM $(r=0.279$,). Our results were in agreement with Mahfouz et al. ${ }^{(13)}$ who found a positive correlation with the duration of DM and NGAL level in T2DM ( $r=0.749, \mathrm{p}=0.01)$. Also our results were consistent with Yang et al. (14) who studied 74 individuals with T2DM and 20 control individuals and found a positive correlation between NGAL and duration of DM ( $\mathrm{r}=0.527, \mathrm{p}=0.06)$. In compliance with our results Kahdem et al. ${ }^{(15)}$ showed significant positive correlation between serum NGAL and duration of diabetes $(\mathrm{r}=0.414, \mathrm{p}=0.02)$.

The typical presentation of diabetic kidney disease is considered to include a long-standing duration of diabetes ${ }^{(16)}$. In patients with T2DM, age and duration of DM increase the risk for diabetic kidney disease ${ }^{(17)}$.

The International Diabetic Nephropathy Study is a prospective cohort study of 243 children and young adults with type 1 diabetes. Subjects between the ages of 9 and 30 years (with a duration of type 1 diabetes of 2-20 years, found that the microvascular complications of type 1 diabetes are known to increase with duration of the disease and the complication of DM begins to increase substantially only after 14 or 15 years duration ${ }^{(\mathbf{1 8})}$.

In our study, there was a positive correlation between NGAL level and $\mathrm{HbA1C}$, with significant value $(r=0.778)$ in patients groups. These results were in agreement with those reported by Mahfouz $\boldsymbol{e t}$ al. (13). That study included 150 patients with T2DM nephropathy. They found that HbA1c in T2DM patients was positively correlated with serum NGAL level with high statistical significance $(\mathrm{r}=0.341, \mathrm{P}=$ 0.001). In agreement with our results, Kahdem et al. (15) who studied 90 subjects showed a positive significant correlation between serum NGAL and HbA1c \% ( $r=0.394, \mathrm{p}=0.03)$.

Our results showed a positive correlation between NGAL and FPG ( $\mathrm{r}=0.562), 2 \mathrm{hPPPG}$ $(\mathrm{r}=0.687)$. These results were in sympathy with Mahfouz et al. ${ }^{(13)}$ who found a positive correlation with NGAL level and FPG $(r=0.626, p=0.0001)$ and $2 \mathrm{hpppG}(\mathrm{r}=0.732, \mathrm{p}=0.001)$. Also, Al-Refai et al. (19), found a significant positive correlation with FPG $(\mathrm{r}=0.732, \mathrm{p}=0.01)$ and $2 \mathrm{hpppG}(\mathrm{r}=0.944, \mathrm{p}=0.004)$.

Diabetic nephropathy often develops in patients with poor glycemic control. The degree of glycemic control is an important predictor of terminal kidney failure. It is generally accepted that the degree of glycemic control is a very important risk factor for the development diabetic nephropathy ${ }^{(20)}$. Many studies of T1DM patients also suggested that HbA1c is affected by the control of DM ${ }^{(21)}$.

In our study, there was a positive correlation between NGAL level and $\mathrm{Alb} / \mathrm{Cr}$ with significant value ( $\mathrm{r}=0.888$ ) in patients groups. This was also in line with Yang $\boldsymbol{e t}$ al. ${ }^{(14)}$ as they found a positive correlation between NGAL and Alb/Cr ( $r=0.932, p<$ 0.001).

\section{CONCLUSION}

Our study showed that there was a high significant difference in the level of urinary NGAL in diabetic patients than control subjects. Urine NGAL had a positive correlation with albumin-creatinine ratio, duration of DM, HbA1c.

\section{REFERENCES}

1. Maeda Y, Suzuki A, Ishii J et al. (2014): Level of urinary liver-type fatty acid-binding protein is associated with cardiac markers and electrocardiographic abnormalities in type-2 diabetes with chronic kidney disease stage G1 and G2. Heart Vessels, 30:362-368.

2. Assal H, Tawfeek S, Rasheed E et al. (2013): Serum cystatin $\mathrm{C}$ and tubular urinary enzymes as biomarkers of renal dysfunction in type 2 diabetes mellitus. Clin Med Insights Endocrinol Diabetes, 6:7-13.

3. An J, Cho Y, Yu H et al. (2009): The clinical characteristics of normoalbuminuric renal insufficiency in Korean type 2 Diabetic Patients: A Possible early stage renal complication. J Korean Med Sci., 24:75-81.

4. Ibrahim M, Ahmed Y, El-Shinnawy H et al. (2015): Value of urinary cystatin $\mathrm{C}$ in early detection of diabetic nephropathy in type 2 diabetes mellitus. Int $\mathbf{J}$ Adv Res Biol Sci., 2: 211-223.

5. Bouvet B, Paparella C, Arriaga $S$ et al. (2014): Evaluation of urinary N-acetyl-beta- Dglucosaminidase as a marker of early renal damage in patients with type 2 diabetes mellitus. Arq Bras Endocrinol Metab., 58:798-801. 
6. Malyszko J, Bachorzewska-Gajewska H, Malyszko J et al. (2010): Serum neutrophil gelatinase-associated lipocalin as a marker of renal function in hypertensive and normotensive patients with coronary artery disease. Nephrology, 13: 153-156.

7. Derosa A, D'Angelo C, Tinelli F et al. (2013): Normoalbuminuric renal-insufficient diabetic patients. Diabetic Care, 33: 129-134.

8. Ambade V, Singh P, Somani B et al. (2015): Urinary $\mathrm{N}$-acetyl beta glucosaminidase and gamma glutamyl transferase as early markers of diabetic nephropathy. Indian J Clin Biochem., 21:142-148.

9. Cockcroft D, Gault M (1976): Prediction of creatinine clearance from serum creatinine. Nephron, 16(1):31-41.

10. Elkhidir A, Eltaher H, Mohamed A (2017): Association of lipocalin-2 level, glycemic status and obesity in type 2 diabetes mellitus. BMC Res Notes, 10(1):285-293.

11. Nielsen S, Schjoedt K, Astrup A et al. (2012): Neutrophil Gelatinase-Associated Lipocalin (NGAL) and Kidney Injury Molecule 1 (KIM1) in patients with diabetic nephropathy: a cross-sectional study and the effects of lisinopril. Diabetic Medicine, 27:1144-50.

12. Ahn H, Hyun C (2013): Evaluation of serum neutrophil gelatinase-associated lipocalin (NGAL) activity in dogs with chronic kidney disease. Veterinary Record, 173: 452-59.

13. Mahfouz M, Assiri A, Mukhtar M (2016): Assessment of neutrophil gelatinase-associated lipocalin (ngal) and retinol-binding protein 4 (rbp4) in type 2 diabetic patients with nephropathy. Biomarker Insights, 8:11-31.
14. Yang Y, He X, Chen S et al. (2009): Changes of serum and urine neutrophil gelatinase-associated lipocalin in type-2 diabetic patients with nephropathy: one-year observational follow-up study. Endocrine, 36: 45-51.

15. Kahdem A, DyabAllawi A, Nada S et al. (2017): Neutrophil gelatinase associated lipocalin (NGAL) in early detection of nephropathy in type 2 diabetic Iraqi patients. J Fac Med Baghdad, 59: 74-78.

16. Afkarian M, Zelnick $L$, Hall Y et al. (2016): Clinical manifestations of kidney disease among US Adults with diabetes, JAMA., 316:602-610

17. Parving H, Persson F, Lewis J et al. (2008): AVOID study investigators. Aliskiren combined with losartan in type 2 diabetes and nephropathy. N Engl J Med., 358:2433-46.

18. West K, Erdreich I, Tober J (2007): A detailed study of risk factors for retinopathy and nephropathy in diabetes. Diabetes, 29:501 -508.

19. Al-Refai A, Tayel S, Ragheb A et al. (2014): Urinary neutrophil gelatinase associated lipocalin as a marker of tubular damage in type 2 diabetic patients with and without albuminuria. Open Journal of Nephrology, 4:37-66.

20. Maric C, Mankhey R, Wells C et al. (2011): Altered glycosylation of Tamm-Horsfall glycoprotein derived from renal allograft recipients lead to changes in the biological function. Transpl Immunol., 18:237-245.

21. Acton K, Shields R, Rith-Najarian S (2004): Applying the diabetes quality improvement project indicators in the Indian health service primary care setting. Diabetes Care, 24:22-26. 